\title{
Maternal and Neonatal Outcome of Teenage Pregnancy at Al-Galaa Maternity Teaching Hospital, Cairo, Egypt
}

\author{
Azza M. Alyamani' ${ }^{1}$, Hanan A. Elewa ${ }^{1}$, Fatma A. Newira ${ }^{2}$ \\ ${ }^{1}$ Department of Obstetrics and Gynecology, Faculty of Medicine, Al-Azhar University, Cairo, Egypt \\ ${ }^{2}$ Department of Obstetrics and Gynecology, Al-Galaa Maternity Teaching Hospital, Cairo, Egypt \\ Email: *drazza2004@hotmail.com
}

How to cite this paper: Alyamani, A.M., Elewa, H.A. and Newira, F.A. (2021) Maternal and Neonatal Outcome of Teenage Pregnancy at Al-Galaa Maternity Teaching Hospital, Cairo, Egypt. Open Journal of Obstetrics and Gynecology, 11, 591-601. https://doi.org/10.4236/ojog.2021.115055

Received: September 10, 2020

Accepted: May 21, 2021

Published: May 24, 2021

Copyright $\odot 2021$ by author(s) and Scientific Research Publishing Inc. This work is licensed under the Creative Commons Attribution International License (CC BY 4.0).

http://creativecommons.org/licenses/by/4.0/

(c) (i) Open Access

\begin{abstract}
Backgrounds: Teenage pregnancies are generally considered as a high-risk however, sufficient data is lacking in the area, Cairo Egypt. We attempted to determine whether teenage pregnancies show poorer outcomes than adult-age pregnancies. Objectives. Finding out the prevalence of teenage pregnancy and its maternal and fetal outcome in comparison. Subjects and methods. A retrospective analytical case-control study was conducted on patients who had attended for delivery at Al-Galaa Maternity Teaching Hospital during the period of one year from March 2015 to February 2016. A total of included 538 patients aged 16 - 19 years as study group and adult age group: included 609 patients aged 25 - 29 years as the control group. The only primigravid was enrolled. The study records were retrieved for review. Comparisons were made between the two groups regarding maternal demographics, socioeconomic status, medical disorders, major antenatal complications, the outcome of labor, mode of delivery, and perinatal complications. Results: The prevalence of teenage pregnancy, was $46.9 \%$. Teenage group, compared with the adult group, P-value $<0.05$ was considered the significant prevalence of teenage pregnancy, was $46.9 \%$. Teenage group, compared with the adult group, $\mathrm{P}$-value $<0.05$ was considered significant. Teenagers had a lower antenatal care attendance $(63.8 \%$ vs $76.7 \% ; \mathrm{P}=0.001)$, a higher incidence of Eclampsia ( $2.1 \%$ vs $0 \% ; \mathrm{P}=0.000)$, vaginal deliveries $(70.1 \%$ vs $51.9 \% ; \mathrm{P}=0.000)$. And a higher maternal ICU admission ( $1.4 \%$ vs $0.0 .7 \%)$, and maternal death $(0.5 \%$ vs $0 \%$ ),especially in low socioeconomic. On the other hand, the adult group pregnancies had a higher incidence of gestational hypertension, gestational diabetes, and cesarean delivery. Conclusions: Teenager primigravid women should be considered as a high-risk pregnancy and thus require special medical attention to avoid adverse maternal and neonatal outcomes.
\end{abstract}




\section{Keywords}

Teenage Pregnancy, Primigravid, Obstetric Outcome, Neonatal Outcome

\section{Introduction}

Teenage pregnancy is a global phenomenon with clearly known causes, and serious health, social and economic consequences to individuals, families, and communities. An estimated 21 million girls aged 15 to 19 years in developing regions become pregnant every year, and approximately 12 million of them gave birth [1]. However, Adolescent fertility has declined from 56 births per 1000 adolescent women in 2000 to 45 births in 2015 and 44 births in 2019 [2].

Developing countries have distinctly different rates of teenage pregnancy. In Egypt; the incidence of teenage pregnancy is 9.6\% [3]. In developed regions, such as North America and Western Europe, teenage parents tend to be unmarried and adolescent pregnancy is seen as a social issue. On the contrary, teenage parents in developing countries are often married, and their pregnancy may be welcomed by the family and society.

From the biological point of view, the consequences of teenage pregnancy are the high rates of hypertensive disorders of pregnancy, anemia, gestational diabetes, delivery complications, determining an increase in maternal and fetal mortality. It is important to note that some studies showed an increased rate of prenatal, intrapartum, and postpartum inter-current events among them [4].

As to problems with the newborn, gestation during teenage is associated with higher rates of low birth weight (LBW), preterm delivery, respiratory diseases, and birth trauma, besides a higher frequency of neonatal complications and infant mortality [5]. Therefore, to what extent does teenage pregnancy affect the maternal and neonatal outcome? This study aims at finding out the prevalence of teenage pregnancy and its maternal and fetal outcome in comparison to the outcome of pregnancy in adult age at Al-Galaa Maternity Teaching Hospital.

Aim of the work:

Finding out the prevalence of teenage pregnancy and its maternal and neonatal. The outcome in comparison with the outcome of pregnancy in adult age at Al-Gala Maternity Teaching Hospital.

\section{Subjects and Methods}

This analytical case-control study was conducted on full-term primigravida with a singleton pregnancy who attended for delivery at Al-Galaa Teaching Hospital during the period of one year from March 2015 to February 2016. All women were divided according to their age into two age groups; the First group: including women aging from 16 to 19 years old served as a study group and the Second group: including women aging from 25 to 29 years old served as control.

Inclusion Criteria: 
- Full term preeclampsia.

- Age from 16 to 19 and from 25 to 29 years old.

- Low to moderate socioeconomic status.

- Non-smokers.

- No drug abuse or alcohol.

- No history of medications affecting pregnancy like corticosteroid therapy or teratogenic drugs.

Data were retrieved from the hospital records in an especially designed sheet including obstetric and neonatal information for 1147 patients (609 in the adult group and 538 in the teenage group). Medical disorders during pregnancy include anemia (defined as hemoglobin level of less than $10 \mathrm{~g} / \mathrm{dl}$ ), pre-eclampsia (blood pressure equal 140/90 $\mathrm{mmHg}$ or more), pre-eclampsia (Urine analysis by Albustix for diagnosis of proteinuria), eclampsia, and gestational diabetes (with two or more plasma glucose measurements meet or exceed the following thresholds: fasting level of 95 mg per $\mathrm{dL}$, one-hour level of $180 \mathrm{mg}$ per $\mathrm{dL}$, two-hour level of $155 \mathrm{mg}$ per $\mathrm{dL}$ ).

Detailed information including socioeconomic status, antenatal care attendance, post-term labor, induction of labor were recorded. Labor data such as; premature rupture of membranes, chorioamnionitis, meconium aspiration, antepartum hemorrhage, IUGR, malpresentation, mode of delivery, intrapartum or postpartum events, blood transfusion, development of postpartum hemorrhage, maternal ICU admission, and maternal death were also recorded

Neonatal outcome data including body weight (weight at birth of less than 2500 gram was considered LBW), gender, respiratory distress, admission to neonatal intensive care unit (NICU), congenital anomalies, and perinatal death were also recorded.

All retrieved data were noted down in predetermined especially designed maternal and neonatal sheets and subjected to statistical analysis. The obtained data were kept confidential especially the name and address of the parturient women and the collected data were used for the study purpose only.

Statistical analysis:

Was done on a personal computer using SPSS@. Data were collected, tabulated then analyzed using appropriate statistical tests. Numerical data were presented as mean and standard deviation (if normally distributed). The Student t-test was used to compare normally distributed numerical data. $\mathrm{P} \leq 0.05$ was considered statistically significant.

\section{Results (Tables 1)}

Table 1. Demographic characteristics of pregnant women in the studied groups.

\begin{tabular}{cccc}
\hline & Teenage group (No. 538) & Adult group (No. 609) & P-value \\
\hline Age & $16-19$ years old & $25-29$ years old & ----------- \\
Parity & Primigravida & Primigravida & $\mathrm{P}=1$ \\
GA & Term & Term & $\mathrm{P}=1$
\end{tabular}


Continued

\begin{tabular}{lllllll}
\hline & & N & Total & N & Total & P-value \\
\hline \multirow{2}{*}{ Medical care } & Free & 348 & $537^{*}$ & 384 & $607^{* *}$ & \multirow{2}{*}{ P $=0.315$} \\
& Paid & 189 & $537^{*}$ & 223 & $607^{* *}$ & \\
\hline
\end{tabular}

${ }^{*}$ There is one missed case in the teenage group and ${ }^{*}$ two missed cases in the adult group regarding the type of medical care due to missed data in the available patient's records. The prevalence of teenage pregnancy was $46.9 \%$.

Table 2. Frequency of age and socioeconomic state on the attendance of antenatal care.

\begin{tabular}{ccccccccc}
\hline Variable & \multicolumn{7}{c}{ Teenage group (No. 538) } & \multicolumn{7}{c}{ Adult group (No. 609) } \\
\hline & $\mathrm{N}$ & Total & $\%$ & $\mathrm{~N}$ & Total & $\%$ & $\chi^{2}$ & p-value \\
& 329 & $516^{*}$ & 63.8 & 457 & $596^{* *}$ & 76.7 & 12.015 & 0.001 \\
\cline { 2 - 9 } $\begin{array}{c}\text { Antenatal } \\
\text { care }\end{array}$ & \multicolumn{3}{c}{$\begin{array}{c}\text { Lowioeconomic state } \\
\text { (no.732) }\end{array}$} & $\begin{array}{c}\text { Moderate socioeconomic state } \\
\text { (no.412) }\end{array}$ \\
\cline { 2 - 9 } & $\mathrm{N}$ & Total & $\%$ & $\mathrm{~N}$ & Total & $\%$ & $\chi^{2}$ & p-value \\
& 413 & $704^{* * *}$ & 58.7 & 305 & $404^{* * * *}$ & 75.5 & 31.144 & 0.000 \\
\hline
\end{tabular}

*There are 22 missed cases in the teenage group and ${ }^{\star *} 13$ missed cases in the adult group regarding ANC, ${ }^{* * *}$ There are 28 missed cases in the low socioeconomic group and ${ }^{* * *} 8$ missed cases in the moderate socioeconomic group regarding ANC.

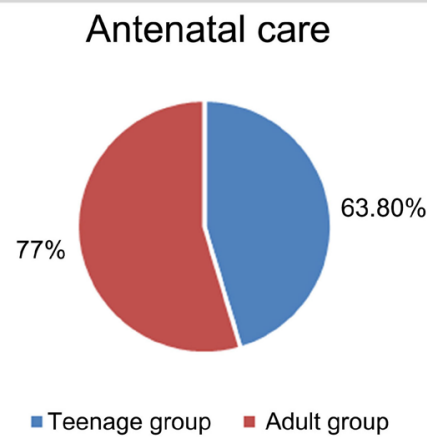

frequency of age in both groups regarding the attendance of antenatal care clinic

\section{Antenatal care}

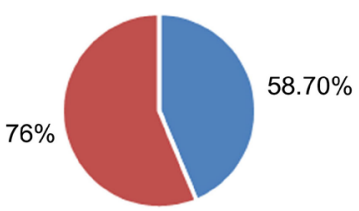

- Low socioeconomic state group

- Moderate socioeconomic state group

frequency of socioeconomic state
in both groups regarding the in both groups regarding the

Figure 1. Frequency of age and socioeconomic state in both groups regarding to the attendance of antenatal care clinic.

Table 3. Age-related medical disorders in the studied groups.

\begin{tabular}{ccccccccc}
\hline \multirow{2}{*}{ Variable } & \multicolumn{7}{c}{ Teenage group (No. 538) } & \multicolumn{7}{c}{ Adult group (No. 609) } \\
\cline { 2 - 8 } & $\mathrm{N}$ & Total & $\%$ & $\mathrm{~N}$ & Total & $\%$ & $\chi^{2}$ & p-value \\
\hline $\begin{array}{c}\text { hypertensive disorders } \\
\text { of pregnancy }\end{array}$ & 10 & $534^{*}$ & 1.9 & 65 & $608^{* *}$ & 10.7 & 21.972 & 0.000 \\
$\begin{array}{c}\text { Pre-eclampsia } \\
\text { Eclampsia }\end{array}$ & 33 & & 6.2 & 87 & & 14.3 & & \\
Gestational Diabetes & 4 & $533^{* * *}$ & 2.1 & 0 & $607^{* * * * *}$ & 0 & 12.015 & 0.001 \\
\hline
\end{tabular}

*There are 4 missed cases in the teenage group and ${ }^{* *}$ a missed case in the adult group regarding hypertensive disorders of pregnancy (PIH), pre-eclampsia, and eclampsia, ${ }^{* *}$ There are 5 missed cases in the teenage group and ${ }^{\star * * *} 2$ missed cases in the adult group regarding gestational diabetes. 


\section{Comment:}

Hypertensive disorders of pregnancy, pre-eclampsia, and gestational diabetes are more prevalent in the adult group as compared to the teenage group with a highly significant difference. However, Eclampsia occurred in 11 patients in the teenage group while no cases occurred in the Adult group.

Table 4. Frequency of mode of delivery in the studied groups.

\begin{tabular}{ccccccccc}
\hline \multirow{2}{*}{ Variable } & \multicolumn{7}{c}{ Teenage group (No. 538) } & \multicolumn{7}{c}{ Adult group (No. 609) } \\
\cline { 2 - 9 } & $\mathbf{N}$ & Total & $\%$ & $\mathrm{~N}$ & Total & $\%$ & $\chi^{2}$ & p-value \\
\hline Induction of labor & $\mathbf{9 7}$ & $537^{\star}$ & 18.1 & $\mathbf{1 4 8}$ & $607^{* *}$ & 24.4 & 6.760 & $\mathbf{0 . 0 0 9}$ \\
NVD & $\mathbf{3 7 7}$ & & 70.1 & $\mathbf{3 1 0}$ & & 51.9 & & \\
C.S & $\mathbf{1 4 3}$ & 538 & 26.6 & $\mathbf{2 8 7}$ & 609 & 47.1 & 30.432 & $\mathbf{0 . 0 0 0}$ \\
Instrumental & $\mathbf{1 8}$ & & 3.3 & $\mathbf{1 2}$ & & 2 & & \\
Postpartum hemorrhage & $\mathbf{1 7}$ & 538 & 3.2 & $\mathbf{3 2}$ & 589 & 5.4 & 3.493 & 0.062 \\
\hline
\end{tabular}

${ }^{\star}$ There is a missed case in the teenage group and ${ }^{*} 2$ missed cases in the adult group regarding induction of labor.

\section{Comment:}

A higher incidence of cesarean section was found in the adult group when compared with the teenage group with a highly significant difference. The table also demonstrates that the incidence of vaginal deliveries was higher in the teenage group compared to the adult group with a highly significant difference as well.
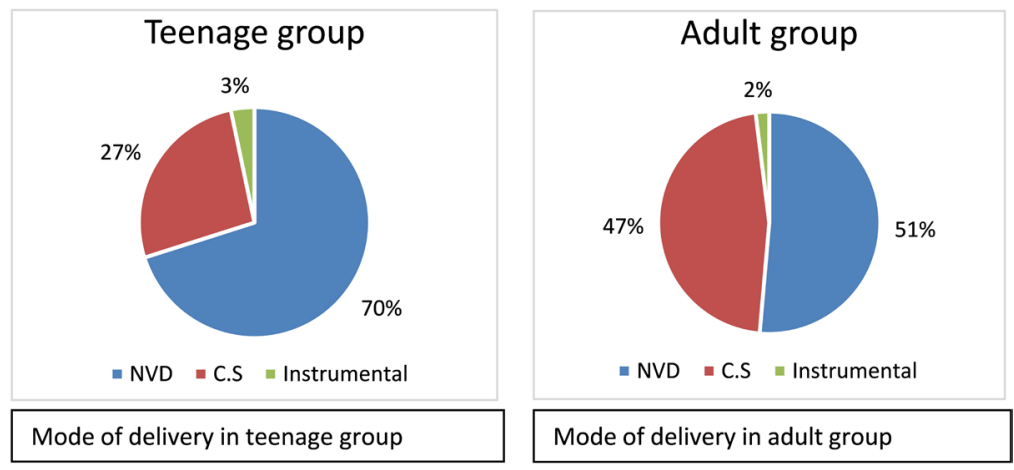

Figure 2. Mode of delivery in both groups.

Table 5. Frequency of socioeconomic status on the management of labor in the studied groups.

\begin{tabular}{lcccccccc}
\hline \multirow{2}{*}{ Variable } & \multicolumn{2}{c}{$\begin{array}{c}\text { Low socioeconomic } \\
\text { (free department) } \\
\text { (No. 732) }\end{array}$} & $\begin{array}{c}\text { Moderate socioeconomic } \\
\text { (paid department) } \\
\text { (No. 412) }\end{array}$ & \\
\cline { 2 - 9 } & $\mathrm{N}$ & Total & $\%$ & $\mathrm{~N}$ & Total & $\%$ & $\chi^{2}$ & p-value \\
\hline MODE OF DELIVERY & & & & & & & & \\
- SVD & 475 & & 64.9 & 206 & & 50 & & \\
- C.S & 230 & 732 & 31.4 & 203 & 412 & 49.4 & 23.87 & 0.000 \\
- Instrumental & 27 & & 3.7 & 3 & & 0.7 & & \\
\hline
\end{tabular}


Continued

\begin{tabular}{ccccccccc}
\hline POSTPARTUM & & & & & & & & \\
COMPLICATIONS & & & & & & & & \\
Postpartum hemorrhage & 35 & 720 & 4.9 & 10 & 405 & 2.5 & 3.862 & 0.049 \\
ICU admission & 10 & 730 & 1.4 & 3 & 411 & 0.7 & 0.956 & 0.328 \\
Maternal Mortality & 4 & 731 & 0.5 & 0 & 411 & 0 & ---- & ---- \\
\hline
\end{tabular}

\section{Comment:}

A higher incidence of cesarean section was found in the moderate socioeconomic state group compared to the low socioeconomic state group with a highly significant difference. We noticed that most of the teenage group was of low socioeconomic levels. It is also accompanied by a decreased incidence of instrumental and vaginal deliveries compared to the group of low socioeconomic state with a significant difference. The incidence of postpartum hemorrhage is higher in the low socioeconomic group as compared to the moderate socioeconomic group with a significant difference.

\section{Discussion}

Teenage pregnancy is an important public health problem worldwide involving Egypt. It often occurs in the context of poor social standards. It is debated whether teenage pregnancy is associated with adverse reproductive outcomes or not. Insufficient accurate reports are available about the situation in Egypt in spite that a significant number of teenage women get married and bear children.

This is in agreement with rates reported by Kongnyuy et al. [6]. In the study done in Cameroon. They found that the maternal factor associated with the adverse outcomes in pregnant teenagers is the low number of antenatal visits $(<4$ visits). In the present study, $63.8 \%$ vs $76.7 \%$ had antenatal care visits in the teenage and the adult groups respectively (Table 2) and (Figure 1). These findings are quite alarming given the importance of such services for safe motherhood and childbirth, especially among primipara who constitute the great majority of teenage pregnancies.

Low attendance of antenatal care in teenagers was often due to lack of experience and failure of the health-care system to convince adolescents of the value of antenatal care, or whether it reflected the consequences of specific social and economic barriers to access to antenatal care by pregnant adolescents [7].

Regarding preeclampsia, the present study results indicated that adult pregnant women developed it more frequently, at a statistically significant difference compared to the teenage women (14.3\% versus $6.2 \%$ respectively) (Table 3 ). This striking finding is supported by Ganchimeg et al. [8] who reported a lower incidence of preeclampsia in pregnant teenagers (2.5\%) compared to adults $(1.8 \%)$ at $\mathrm{P}<0.001$.

On the contrary, Saftlas et al., [9] analyzed data from the National Hospital Discharge Survey for the years 1979 through 1986. This study population consisted of all sampled women of any parity who delivered at the hospital during 
this period. They found that 26 per 1000 or (2.6\%) pregnant teenagers were complicated by preeclampsia. This rate is lower than that reported by most hospital-based studies. The higher rates may be attributed to the many high-risk patients in referral hospitals. Moreover, they concluded that maternal age $<20$ years old is the strongest risk factor for preeclampsia.

A possible explanation of the discrepancy between our results and those of Saftlas et al. [9], is that it may be due to the un-standardized parity in their studies, as all compared pregnant women were of different age groups, but among teenagers, the number of nulliparous women was much higher than among other age groups.

A careful analysis of the literature showed that there is no reason to assume that the incidence of preeclampsia in teenage pregnancies is higher than the incidence in adult women of the same parity [10].

On contrary, we found a higher incidence of eclampsia in a teenage group when compared to the adult group (2.1\% versus $0 \%$ respectively) (Table 3$)$. It was stated that in spite that preeclampsia can occur at lower incidence rates in teenage pregnancies, yet if it develops, the course will be more fulminate and may be fatal rather than in adult women [11]. This indicates that teenage mothers are less careful about ANC during pregnancy because of the lack of awareness and maturity. These findings were proved in our results that showed a lack of ANC in teenagers.

Regarding Diabetes Mellitus (DM), the present study showed a significant increase in gestational diabetes in the adult group compared to the teenage group (5.1\% versus $0.8 \%$ respectively) with a significant difference at $(P=0.001)$ (Table 3).

DM during pregnancy in the USA has increased progressively with maternal age, showing from 8.3 per 1000 singleton live-born infants of maternal age under 20 years old to $16.3,25.1$, and 33.8 per 1000 singleton live-born infants of maternal age 20 - 24, 25 - 29, and 30 - 34 years old, respectively [12].

Furthermore, Danilenko et al. [13], reported that the risk of Gestational Diabetes Mellitus (GDM) becomes significantly increased from 25 years and further. This supports the American Diabetes Association recommendation on the use of age $\geq 25$ years as the cutoff for screening and the observation that maternal age $\geq 25$ years is the factor most predictive of GDM. Other researchers reported similar different incidences of such complications between teenage and adult mothers [14].

Regarding the effect of mother's age on the induction of labor rate, it was found in the current study an increased rate of induction of labor in the adult group compared to the teenage group (24.4\% versus $18.1 \%$ respectively) with a significant difference at $(\mathrm{P}=0.009)$ (Table 4$)$ and (Figure 2). This is in agreement with Jolly et al., [15] who derived their data from the St. Mary's Maternity Information System database and contained data on more than $80 \%$ of all deliveries in the region. They reported a lower incidence of induction of labor or 
oxytocin use in teenagers compared to the adult group (15.9\% versus $16.88 \%$ respectively).

We agree with the concept that the lower incidence of induction of labor in teenagers could be due to the rapid progress of labor in this group [15]. This unpreferred induction of labor in teenagers by doctors might be explained by a different attitude towards pregnant adolescents and towards the management of their delivery by midwives and/or obstetricians [8].

The present study results showed a higher incidence of vaginal delivery in the teenage group when compared to the adult group (70.1\% versus $51.9 \%$ respectively) with a significant difference at $(\mathrm{P}=0.000)$ (Table 4$)$. These results were in agreement with those of $A b b a s$ et al., [16], who found a higher rate of vaginal deliveries in teenagers compared to adults with a significant difference at $(\mathrm{P}=$ 0.005). The explanation may be due to the higher rates of low birth weight in teenage pregnancies.

However, a higher rate of instrumental deliveries was found in teenage pregnancies (3.3\% versus $2 \%$ respectively) with a significant difference at $(\mathrm{P}=0.005)$ (Table 4). The possible explanation could be due to the underdevelopment of the pelvis in teenage mothers. There are strong indications that in very young girls the pelvic bones of the birth canal still be in the process of growing, and are therefore immature, especially in some of the poorer regions in developing countries where the onset of puberty is usually relatively late [8].

The present study results also revealed that there was no statistically significant difference between teenage and adult mothers as regard postpartum hemorrhage (3.2\% versus 5.4\% respectively) (Table 4). This agreed with Abbas et al., [16] a prospective case-control study, conducted at the Labor Ward of Assuot Woman's Health Hospital.

However, we found that postpartum hemorrhage was more prevalent in lower socioeconomic status populations (Free department) in both groups (4.9\% versus $2.5 \%$ respectively) with a significant difference at $(\mathrm{P}=0.049)$ (Table 5$)$. This was consistent with previous reports' results [17] [18].

Our study results found an increased incidence of maternal ICU admission in low socioeconomic status compared to moderate one $(1.4 \%$ versus $0.7 \%)$ and the maternal mortality in teenagers compared to adults ( $0.5 \%$ versus $0 \%)$ (Table 5). This is in agreement with some hospital-based studies in developing countries. A study in a hospital in Nigeria reported 25 maternal deaths in adolescents aged 10 - 19 years old [19].

The present study results showed also a higher incidence of vaginal delivery in the low socioeconomic group (Free department) when compared to the moderate socioeconomic group (Paid department) (64.9\% versus 50\% respectively) (Table 5).

This is in agreement with Fairley et al., [20] who stated that women with low socioeconomic status or who living in deprived areas were less likely to give birth to CS compared to women with moderate socioeconomic status or who 
live in affluent areas, even in countries with publicly funded healthcare.

The higher prevalence of CS births among women with moderate socioeconomic state might partially be explained by an increased risk of adverse outcomes in this group and indicating that inequity may exist in some healthcare services.

Based on available study results, teenage primigravidae should be considered a high-risk pregnancy, who requires certain medical and antenatal care to avoid adverse maternal events such as eclamptic fits and instrumental delivery ,ICU admission, especially in the low socioeconomic.

Paying more attention to the low socioeconomic population will enhance their chance to avoid many complications. We should never deny their right to receive an equal medical service as those in the higher socioeconomic group.

\section{Conclusions}

- Based on this study results, we conclude that teenage primigravida women should be considered high-risk pregnancies.

- Close antenatal care for such cases during all stages of pregnancy and delivery helps us avoid adverse maternal outcomes especially "Eclamptic fits" and adverse neonatal outcomes as well.

- Delivery of a teenager should be in a well-equipped hospital as they are more liable to eclamptic fits, malpresentation, and ICU admission.

- The free department needs more attention and care to avoid the occurrence of maternal complications.

\section{Recommendations}

- This study recommends that healthcare providers should anticipate and screen for high-risk teenage pregnant women. Paramedics should be aware of the scope of the problem and encourage teenagers to seek antenatal care and promote the importance of delivery in well-equipped hospitals.

- Paying attention to mass media campaigns to help raise public awareness about the risks and adverse outcomes of early marriage and teenage pregnancy.

- A larger scale of similar studies should be held in different areas and university hospitals around Egypt. This will help researchers obtain a comparative model of different outcomes from different areas and governates Generalised recommendations could be also obtained.

\section{Conflicts of Interest}

The authors declare no conflicts of interest regarding the publication of this paper.

\section{References}

[1] Darroch, J., Woog, V., Bankola, A. and Ashford, L. (2016) Adding It Up: Costs and Benefits of Meeting the Contraceptive Needs of Adolescents. Guttmacher Institute, 
New York.

[2] Sustainable Development Goals Knowledge Platform: Progress and Information 2019. https://sustainabledevelopment.un.org/sdg3

[3] EDHS (Egypt Demographic and Health Survey) (2008) Teenage Pregnancy and Motherhood. ICF International, Fairfax.

[4] Iacobelli, S., Robillard, P., Gouyon, J., Hulsey, T., Barau, G. and Bonsante, F. (2012) Obstetric and Neonatal Outcomes of Adolescent Primiparous Singleton Pregnancies: A Cohort Study in the South of Reunion Island, Indian Ocean. Journal of Maternal-Fetal and Neonatal Medicine, 25, 2591-2596. https://doi.org/10.3109/14767058.2012.718003

[5] Rocha, R., Souza, E., Guazzelli, C., Chambô, A., Soares, E. and Nogueira, E. (2006) Prematuridade e baixo peso entre recém-nascidos de adolescentes primiparas. $R e$ vista Brasileira de Ginecologia e Obstetrícia, 28, 530. https://doi.org/10.1590/S0100-72032006000900005

[6] Kongnyuy, E., Nana, P., Fomulu, N., Wiysonge, S. and Kouam, L. (2008) Adverse Perinatal Outcomes of Adolescent Pregnancies in Cameroon. Maternal and Child Health Journal, 12, 149-154. https://doi.org/10.1007/s10995-007-0235-y

[7] World Health Organization (2017) Managing Complications in Pregnancy and Childbirth: A Guide for Midwives and Doctors. No. 2, 87.

[8] Ganchimeg, T., Ota, E., Morisaki, N., Laopaiboon, M., Lumbiganon, P., Zhang, J., Yamdamsuren, B., Temmerman, M., Say, L., Tunc, A., Vogel, J., Souza, J. and Mori, R. (2014) Pregnancy and Childbirth Outcomes among Adolescent Mothers: A World Health Organization Multicountry Study. BJOG, 121, 40-48.

https://doi.org/10.1111/1471-0528.12630

[9] Saftlas, A., Olson, D., Franks, A., Atrash, H. and Pokras, R. (1990) Epidemiology of Preeclampsia in the United States, 1979-1986. The American Journal of Obstetrics and Gynecology, 163, 460-465. https://doi.org/10.1016/0002-9378(90)91176-D

[10] Thato, S., Rachukul, S. and Sopajaree, C. (2007) Obstetrics and Perinatal Outcome of Thai Pregnant Adolescents: A Retrospective Study. International Journal of Nursing Studies, 44, 1158-1164. https://doi.org/10.1016/j.ijnurstu.2006.05.016

[11] Abdelsattar, M. (2016) Teenage Pregnancy in Upper Egypt. International Journal of Advanced Research in Biological Sciences, 3, 35.

[12] CDC (Center for Disease Control and Prevention) (2011) Diabetes and Prediabetes during Pregnancy-United States. National Diabetes Fact Sheet. Morbidity and Mortality Weekly Report, 47, 408.

[13] Danilenko, D., Van, W., Nelson, R. and Ogburn, P. (1999) Universal versus Selective Gestational Diabetes Screening: Application of 1997 American Diabetes Association Recommendations. The American Journal of Obstetrics and Gynecology, 181, 798-802. https://doi.org/10.1016/S0002-9378(99)70304-2

[14] Sa-ngiamsak, P. (2016) The Life Experiences of Unmarried Teenage Mothers in Thailand. The American Journal of Managed Care, 18, 96.

[15] Jolly, M., Sebire, N., Harris, J., Robinson, S. and Regan, L. (2012) Obstetric Risks of Pregnancy in Women Less than 18 Years Old. Obstetrics \& Gynecology, 96, 962966. https://doi.org/10.1097/00006250-200012000-00018

[16] Abbas, A., Ali, S., Ali, M., Fouly, H. and Altraigey, A. (2017) The Maternal and Neonatal Outcomes of Teenage Pregnancy in a Tertiary University Hospital in Egypt. Proceedings in Obstetrics and Gynecology, 7, 34.

https://doi.org/10.17077/2154-4751.1350 
[17] Soubhagya, T. and Venketesh, G. (2012) Outcome of Teenage Pregnancy. JDMS, 6, 81-83. https://doi.org/10.9790/0853-0668183

[18] Lindquist, A., Knight, M. and Kurinczuk, J. (2013) Variation in Severe Maternal Morbidity According to Socioeconomic Position: A UK National Case-Control Study. BMJ Open, 3, e002742.

[19] Ujah, I., Aisien, O., Mutihir, J., Vanderjagt, D., Glew, R. and Uguru, V. (2005) Maternal Mortality among Adolescent Women in Jos, North-Central, Nigeria. Journal of Obstetrics and Gynaecology, 25, 3-6. https://doi.org/10.1080/01443610400023395

[20] Fairley, L., Dundas, R. and Leyland, A. (2011) The Influence of Both Individual and Area-Based Socioeconomic Status on Temporal Trends in Caesarean Sections in Scotland 1980-2000. BMC Public Health, 11, Article No. 330.

https://doi.org/10.1186/1471-2458-11-330 